DOI: https://doi.org/10.30598/TRITONvol15issue1page21-29

\title{
ANALISIS KESESUAIAN DAN DAYA DUKUNG DAERAH REHABILITASI LAGUNA BESAR DAN SLOPE REEF LAGUNA KIPUO, NEGERI IHAMAHU
}

\section{(Suitability and Carrying Capacity Analyses of Coral Reef Rehabilitation Area at Laguna Besar and Slope Reef Laguna Kipuo, Ihamahu Village)}

\author{
Y. Tanamal ${ }^{1 *}$, S. F. Tuhumury ${ }^{2}$, dan M. Sangaji ${ }^{2}$ \\ ${ }^{1}$ Program Studi Manajemen Sumberdaya Kelautan dan Pulau-Pulau Kecil \\ Pascasarjana Universitas Pattimura \\ ${ }^{2}$ Jurusan Budidaya Perairan Fakultas Perikanan dan Ilmu Kelautan Universitas Pattimura \\ ${ }^{3}$ Jurusan Manajemen Sumberdaya Perairan Fakultas Perikanan dan Ilmu Kelautan Universitas Pattimura \\ fredo.tanamal@yahoo.com
}

\begin{abstract}
ABSTRAK : Ekosistem terumbu karang merupakan salah satu ekosistem pesisir yang peranan penting baik secara ekologi maupun ekonomi. Terumbu karang telah mengalami kerusakan pada daerah laguna Negeri Ihamahu akibat tekanan aktivitas masyarakat. Penelitian dilakukan di perairan Negeri Ihamahu tepatnya di Laguna Besar dan Slope Reef (Labuang) Laguna Kipuo, Negeri Ihamahu, Kecamatan Saparua Timur, Kabupaten Maluku Tengah pada Maret-Agustus 2018. Tujuan penelitian ini yaitu menganalisis kesesuaian daerah rehabilitasi terumbu karang di Laguna dan menganalisis daya dukung dalam pengelolaan daerah rehabilitasi terumbu karang di daerah Laguna. Pengumpulan data primer diperoleh melalui pengamatan secara langsung meliputi kondisi terumbu karang, parameter penunjang transplantasi karang, penyebaran kuisioner, dan wawancara langsung masyarakat di Negeri Ihamahu. Data sekunder dikumpulkan melalui literatur-literatur dari berbagai penelitian terkait sebelumnya. Hasil analisis menunjukkan bahwa kondisi terumbu karang berada pada kategori rusak. Parameter yang dipakai untuk menganalisis kesesuaian transplantasi karang menghasilkan kedua lokasi sudah sesuai untuk dilakukan transplantasi karang. Luas lahan rehabilitasi terumbu karang pada stasiun 1 adalah 4,45 Ha dengan daya dukung sebanyak 988.890 substrat buatan, stasiun 2 sebanyak 200.000 substrat buatan dengan luas areal rehabilitasi 0,90 Ha. Kegiatan rehabilitasi dengan teknik transplantasi ini didukung $100 \%$ oleh masyarakat.
\end{abstract}

Kata Kunci : Terumbu karang, rehabilitasi, transplantasi, laguna, daya dukung

ABSTRACT : Coral reef ecosystem in the one of the coastal ecosystems which have an important role both ecologically and economically. Coral reef in Ihamahu Village have been damaged at lagoon area due to pressure of community activities. This research was carried out at Laguna Besar and Slope Reef (Labuang) Laguna Kipuo, Ihamahu Village, East Saparua District, Central Maluku on March to August 2018. The purposes of the research were: to analyze the suitability and support capacity of the area for coral reefs rehabilitation in lagoon as well as to analyze social support of the community for the management of coral reefs rehabilitation area. The primary data was collected directly through observing the condition of coral reefs and supporting parameters of coral transplantation, distributing questionnaire, and 
interviewing the community of Ihamahu village, while the secondary data was collected through relevance literature from some previous research. The result showed that the condition of coral reefs was damaged. The parameters used to analyze the suitability of coral transplantation showed that both areas were suitable for coral transplantion. The area of coral reefs rehabilitation at station 1 was 4.45 ha which is able to accommodate 988,980 artificial block substrates, while stasion 2 had 0.90 ha with 200,000 artificial block substrates. The result also showed that $100 \%$ of Ihamahu Villagers supported this program.

Keywords : Coral reef, rehabilitation, transplantation, lagoon, carrying capacity

\section{PENDAHULUAN}

Terumbu karang merupakan salah satu ekosistem dari tiga ekosistem di pesisir yang sangat penting karena menjadi sumber kehidupan bagi beragam spesies laut. Terumbu karang memiliki manfaat ekologi dan ekonomi. Menurut Sukmara et al. (2001), manfaat ekologi terumbu karang antara lain sebagai habitat hidup, tempat berkembang, mencari makan, serta tempat memijah berbagai biota laut. Menurut Ardiansyah, dkk. (2013), manfaat ekonomi terumbu karang bagi manusia yaitu dapat menciptakan lapangan pekerjaan dan pemenuhan kebutuhan hidup.

Peranan dan fungsi terumbu karang di pesisir akan tetap stabil jika pemanfaatan sumberdaya di ekosistem terumbu karang oleh manusia tidak menimbulkan dampak negative. Jika manusia hanya memanfaatkan sumberdaya pada ekosistem terumbu karang untuk kebutuhan ekonomi tanpa memperdulikan peranan dan fungsi utama ekosistem terumbu karang, maka tentunya akan merusak ekosistem tersebut. Ekploitasi yang berlebihan terhadap terumbu karang dan sumberdayanya, perubahan lahan atas yang menyebabkan sedimentasi dan kegiatan antropogenik lainnya akan menyebabkan kerusakan terumbu karang (Harvey, et al., 2018).

Tekanan pada ekosistem terumbu karang telah terjadi di Laguna Negeri Ihamahu. Siahainenia, $d k k$. (2017) menyatakan presentase karang hidup di ekosistem laguna, Negeri Ihamahu memiliki kondisi karang telah rusak yang disebabkan oleh berbagai faktor, salah satu penyebab utama adalah tekanan aktivitas manusia (anthropogenic stressor). Berdasarkan kondisi tersebut maka dilakukanlah upaya pengelolaan terumbu karang yang berbasis pada rehabilitasi terumbu karang dengan metode transplantasi karang sebagai langkah awal yang bertujuan untuk pemulihan ekosistem terumbu karang di kawasan ekosistem laguna tersebut. Penelitian ini bertujuan untuk kesesuaian daerah rehabilitasi terumbu karang pada daerah laguna dan menganalisis daya dukung dan dukungan sosial masyarakat dalam pengelolaan rehabilitasi terumbu karang pada daerah laguna.

\section{METODE PENELITIAN}

Penelitian ini dilakukan di kawasan perairan Ihamahu yaitu Laguna Besar dan Labuang Laguna Kipuo (Gambar 1) pada Maret-Agustus 2018 yang terletak pada posisi 30³0'45" LS-12841'11.191" BT pada stasiun 1 (Laguna Besar) dan 30 30'23" LS$128^{\circ} 41^{\prime} 16.273^{\prime \prime}$ BT pada stasiun 2 (Labuang Laguna Kipuo).

Pengumpulan data kondisi lingkungan fisik kimia meliputi suhu, salinitas, kekeruhan air, kecerahan kolom perairan, arus dan gelombang. Paremeter kedalaman terumbu karang yang akan ditransplantasi diukur menggunakan Deep gauge. Metode visual digunakan untuk mengamati keterlindungan, paparan terumbu dan tipe substrat dasar. Data mengenai dukungan sosial masyarakat terhadap rehabilitasi terumbu karang diperoleh melalui wawancara dan pengisian kuisioner. Metode analisis data yang digunakan untuk melengkapi penelitian ini antara lain: analisis kesesuaian lokasi dan indeks rehabilitasi terumbu karang (Sahetapy, 2016) dapat dilihat pada Tabel 1. 


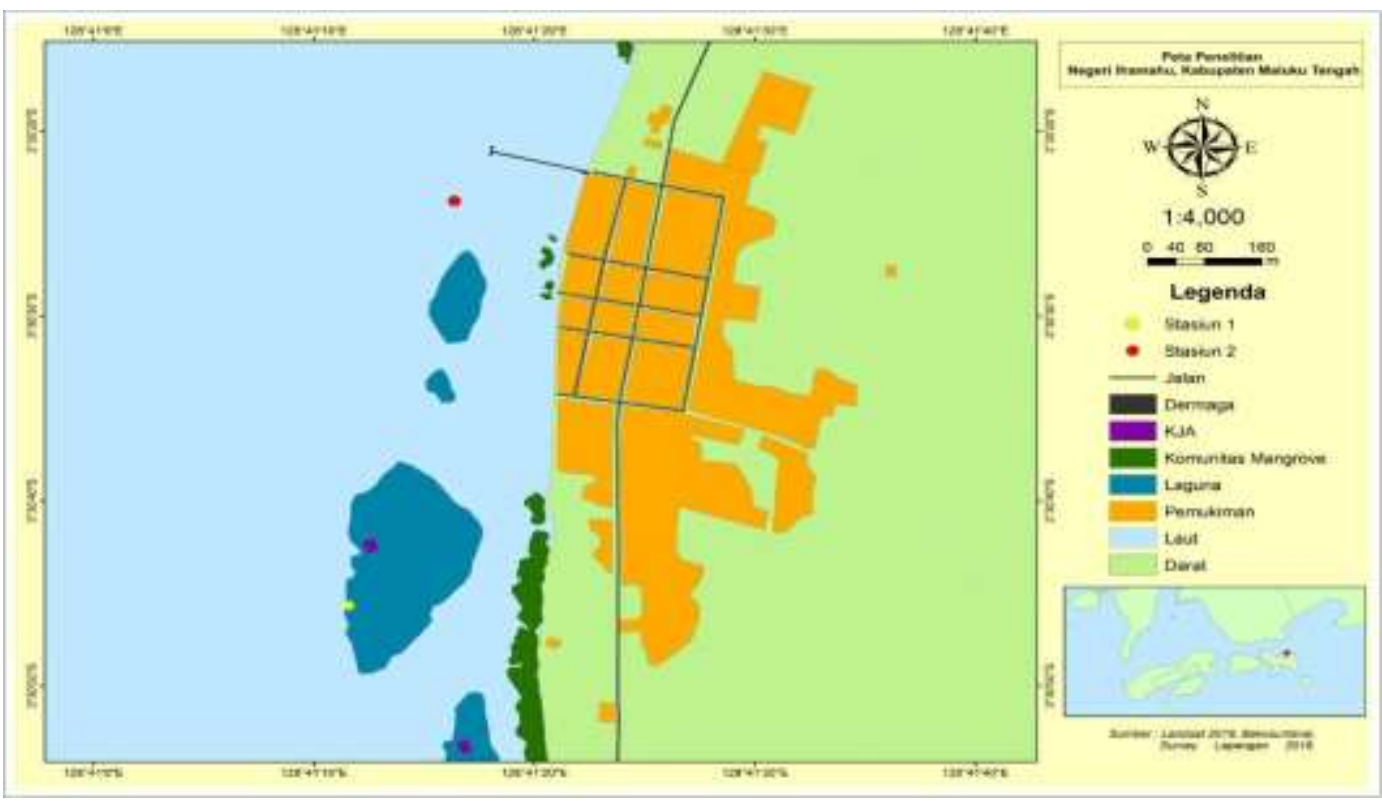

Gambar 1. Peta lokasi penelitian

Tabel 1. Matriks kriteria parameter lingkungan biofisik perairan dengan bobot, kelas dan skor untuk kesesuaian rehabilitasi terumbu karang melalui metode transplantasi

\begin{tabular}{|c|c|c|c|c|c|c|c|}
\hline \multirow{2}{*}{ Parameter } & \multirow{2}{*}{ Bobot } & \multicolumn{2}{|l|}{ S1 } & \multicolumn{2}{|l|}{ S2 } & \multicolumn{2}{|l|}{ S3 } \\
\hline & & Kelas & Skor & Kelas & Skor & Kelas & Skor \\
\hline Kedalaman TK (m) & 4 & $3-7$ & 3 & $8-15$ & 2 & $<3$ atau $>15$ & 1 \\
\hline Kecerahan air & 4 & Tinggi/Cerah & 3 & Sedang/kurang cerah & 2 & Rendah/Tidak cerah & 1 \\
\hline Kekeruhan air & 4 & Rendah (bebas sedimen) & 3 & Sedang (agak keruh) & 2 & Tinggi (keruh) & 1 \\
\hline Suhu $\left({ }^{\mathrm{O}} \mathrm{C}\right)$ & 4 & $25-29$ & 3 & $23-35$ & 2 & $<23$ atau $>35$ & 1 \\
\hline Salinitas (\%o) & 4 & $31-36$ & 3 & 30 atau $>36$ & 2 & $<30$ & 1 \\
\hline Kecepatan arus (m/dt) & 4 & $0,3-0,4$ & 3 & $0,1-<0,3$ & 2 & $<0,1$ & 1 \\
\hline Gelombang (Ombak) & 3 & Agak Berombak & 3 & Kurang berombak & 2 & Tenang & 1 \\
\hline Tipe substrat dasar & 3 & $\begin{array}{c}\text { Keras (Rock, Dead coral, } \\
\text { Rubble) }\end{array}$ & 3 & $\begin{array}{l}\text { Semi lunak (Rubbles } \\
\text { dan Pasir) }\end{array}$ & 2 & Lunak (Pasir), lumpur & 1 \\
\hline Paparan terumbu & 2 & Relatif datar & 3 & Agak curam & 2 & Curam & 1 \\
\hline Keterlindungan & 2 & Relatif Terbuka & 3 & Cukup terlindung & 2 & Terlindung & 1 \\
\hline $\begin{array}{c}\text { Penutupan karang } \\
\text { batu (\%) }\end{array}$ & 1 & $<25-<50$ & 3 & $50-75$ & 2 & $>75$ & 1 \\
\hline $\begin{array}{l}\text { Jarak sumber bibit } \\
\text { Induk karang }(\mathrm{m})\end{array}$ & 1 & $<100-300$ & 3 & $300-500$ & 2 & $>500$ & 1 \\
\hline Total Bobot x Skor & & 108 & & 72 & & 36 & 12 \\
\hline
\end{tabular}

Sumber: Sahetapy (2016)

Untuk menganalisis indeks kesesuaian lahan rehabilitasi terumbu karang yang telah rusak pada Laguna, digunakan formula (Sahetapy, 2016):

$$
\mathbf{I K R}=\left(\frac{N i}{N \max }\right) \mathrm{X} 100 \%
$$

\section{Keterangan :}

IKR = Indeks Kesesuaian Rehabilitasi terumbu karang

$\mathrm{Ni}=$ Nilai parameter ke-i (bobot $\mathrm{x}$ skor)
$\mathrm{N}_{\text {maks }}=$ Nilai maksimum parameter kesesuaiai rehabilitasi TK

Jumlah $=$ Skor $\mathrm{x}$ Bobot

Kriteria atau kelas kesesuaian lahan untuk rehabilitasi terumbu karang ditentukan sebagai berikut: S1: Sangat sesuai, dengan nilai Kelas (> 75-100\%); S2: Sesuai, dengan nilai Kelas $(50-75 \%)$; dan S3: Tidak sesuai, dengan nilai Kelas $(<50 \%)$. 
Analisis Daya Dukung Lahan (DDL) Rehabilitasi dengan Teknik Blok Tansplantasi karang dengan formula (Sahetapy, 2016):

$$
D D R=\frac{L_{k l} R}{L_{b s} T}
$$

Keterangan:

DDR : Daya Dukung Rehabilitasi

$L_{k l} R \quad$ : Luas kapasitas lahan terumbu karang rusak untuk Rehabilitasi

$L_{b s} T \quad$ : Luasan blok semen metode Transplantasi karang

Analisis Dukungan Sosial Masyarakat menggunakan formula yang dikeluarkan oleh KKJI, Dirjen KP3K, KKP RI. (2014) adalah sebagai berikut:

$$
\mathrm{Am}=\left(\frac{\mathrm{Eps}}{\mathrm{Epo}}\right) \times 100 \%
$$

Keterangan :

$\mathrm{Am}=$ dukungan masyarakat

Aps = Jumlah penduduk yang setuju

Epo = Jumlah responden

Penilaian terhadap hasil analisis dari parameter tersebut adalah sebagai berikut:

Kriteria penilaian :

AM $\geq 75 \%=$ mendukung

AM $40-75 \%$ = cukup mendukung

AM $\geq 40 \%=$ tidak mendukung

\section{HASIL DAN PEMBAHASAN}

\section{Kesesuaian Parameter Rehabilitasi}

Kesesuaian parameter rehabilitasi adalah parameter yang diperuntukan untuk menunjang pertumbuhan karang yang dikhususkan pada kegiatan rehabilitasi terumbu karang melalui teknik tranplantasi. Kesesuaian parameter ini akan dinyatakan berhasil jika diikuti dengan benar. Sebaliknya proses rehabilitasi terumbu karang dengan menggunakan teknik transplantasi juga bisa mengalami kegagalan, jika dalam melaksanakan rehabilitasi terumbu karang tidak mempertimbangkan dengan benar kondisi biofisik lingkungan yang menunjang pertumbuhan terumbu karang itu sendiri. Menurut Madduppa, et al., (2016) dan Saleky et al. (2016), terumbu karang yang hidup pada kualitas lingkungan perairan yang baik akan lebih mudah dikelola untuk dilakukan rehabilitasi, sebaliknya untuk lingkungan perairan yang kualitasnya lebih rendah, terlebih dahulu dilakukan perbaikan lingkungan perairannya.

Parameter kesesuaian yang dimodifikasi oleh Sahetapy (2016) untuk kegiatan rehabilitasi dengan teknik transplantasi karang meliputi kedalaman terumbu karang, kecerahan air, kekeruhan air, suhu, salinitas, kecepatan arus, gelombang (ombak), tipe substrat, paparan terumbu, keterlindungan, presentase karang batu dan jarak bibit induk karang (Tabel 2).

\section{a. Kedalaman Terumbu Karang}

Kedalaman suatu perairan sangat menentukan keberhasilan pertumbuhan transplantasi karang berkaitan dengan banyaknya intensitas cahaya yang dibutuhkan oleh zooxanthellae untuk proses fotosintesis. Sedikit cahaya yang diserap akan menghambat proses fotosintesis, dan menghambat kelangsungan hidup.

Berdasarkan hasil penelitian, kedua stasiun transplantasi karang masih berada pada kedalaman yang tembus cahaya. Kedalaman perairan stasiun 1 sebesar $4 \mathrm{~m}$ saat pasang naik, dan pada stasiun 2 adalah $7 \mathrm{~m}$ saat pasang naik. Menurut Nybakken (1992), Pertumbuhan terumbu karang yang pesat ada pada kedalaman rata-rata $2-15 \mathrm{~m}$, dan cahaya merupakan faktor utama yang mempengaruhi distribusi vertikalnya. Matriks kriteria parameter lingkungan biofisik perairan untuk kesesuaian rehabilitasi terumbu karang menunjukkan bahwa kedua stasiun ini termasuk kategori sangat sesuai untuk dilakukan transplantasi karang.

\section{b. Kecerahan Air}

Kecerahan perairan merupakan ukuran yang sangat diperlukan untuk kegiatan transplantasi karang. Karang yang ditransplantasi sebaiknya memiliki perairan dengan tingkat kecerahan tinggi demi menunjang pertumbuhan karang karena walaupun karang merupakan hewan tetapi mikroalga yang terdapat dalam tubuh karang juga membutuhkan cahaya matahari untuk proses fotosintesis. Menurut Luthfi, $d k k$. (2017), Semakin bagus intensitas cahaya matahari yang diterima oleh karang maka tingkat keberhasilan settlement lebih tinggi. 
DOI: https://doi.org/10.30598/TRITONvol15issue1page21-29

Tabel 2. Kesesuaian parameter rehabilitasi stasiun 1 dan stasiun 2

\begin{tabular}{|c|c|c|c|c|c|c|c|}
\hline \multirow[b]{2}{*}{ Parameter } & \multirow[b]{2}{*}{ Bobot } & \multicolumn{2}{|l|}{ S1 } & \multicolumn{2}{|l|}{ S2 } & \multirow{2}{*}{$\begin{array}{c}\text { St } 1 \\
\text { (Laguna } \\
\text { Besar) }\end{array}$} & \multirow{2}{*}{$\begin{array}{c}\text { St } 2 \\
\text { Labuang } \\
\text { Laguna } \\
\text { Kipuo }\end{array}$} \\
\hline & & Kelas & Skor & Kelas & Skor & & \\
\hline Kedalaman TK (m) & 4 & $3-7$ & 3 & $8-15$ & 2 & 3 & 3 \\
\hline Kecerahan air & 4 & Tinggi/Cerah & 3 & Sedang/kurang cerah & 2 & 3 & 3 \\
\hline Kekeruhan air & 4 & Rendah (bebas sedimen) & 3 & Sedang (agak keruh) & 2 & 3 & 3 \\
\hline Suhu $\left({ }^{\circ} \mathrm{C}\right)$ & 4 & $25-29$ & 3 & $23-35$ & 2 & 3 & 3 \\
\hline Salinitas (\%o) & 4 & $31-36$ & 3 & 30 atau $>36$ & 2 & 3 & 3 \\
\hline Kecepatan arus (m/dt) & 4 & $0,3-0,4$ & 3 & $0,1-<0,3$ & 2 & 2 & 3 \\
\hline Gelombang (Ombak) & 3 & Agak Berombak & 3 & Kurang berombak & 2 & 3 & 3 \\
\hline Tipe substrat dasar & 3 & $\begin{array}{c}\text { Keras (Rock, Dead coral, } \\
\text { Rubble) }\end{array}$ & 3 & $\begin{array}{l}\text { Semi lunak (Rubbles } \\
\text { dan Pasir) }\end{array}$ & 2 & 2 & 3 \\
\hline Paparan terumbu & 2 & Relatif datar & 3 & Agak curam & 2 & 3 & 3 \\
\hline Keterlindungan & 2 & Relatif Terbuka & 3 & Cukup terlindung & 2 & 2 & 3 \\
\hline Penutupan karang batu (\%) & 1 & $<25-<50$ & 3 & $50-75$ & 2 & 3 & 3 \\
\hline $\begin{array}{c}\text { Jarak sumber bibit Induk } \\
\text { karang }(\mathrm{m})\end{array}$ & 1 & $100-300$ & 3 & $>300-500$ & 2 & 3 & 3 \\
\hline Total Bobot x Skor & & 108 & & 72 & & 99 & 108 \\
\hline
\end{tabular}

Hasil pengukuran kecerahan perairan pada kedua stasiun tergolong tinggi hingga dasar periran. Berdasarkan matriks kriteria parameter lingkungan biofisik perairan untuk kesesuaian rehabilitasi terumbu karang melalui metode transplantasi maka hasil pengukuran kecerahan pada kedua stasiun menunjukkan relatif tinggi atau cerah, yang berarti ke dua stasiun ini sangat sesuai untuk dilakukan transplantasi karang. Kondisi ini diperkuat dengan penelitian Sahetapy (2018) yang mendapatkan hasil bahwa kecerahan di perairan Negeri Ihamahu dari kedalaman $1 \mathrm{~m}$ hingga $10 \mathrm{~m}$ masih tergolong tinggi.

\section{c. Kekeruhan Air}

Kekeruhan air di kawasan terumbu karang menjadi salah satu indikator penting pertumbuhan terumbu karang. Saat tingkat kekeruhan tinggi maka akan menyebabkan zooxanthellae menjadi stress, kemudian zooxanthellae tersebut meninggalkan bibit karang dan terjadilah bleaching hingga menyebabkan kematian karang. Fakta yang terjadi di kedua stasiun transplantasi karang di perairan Negeri Ihamahu adalah kekeruhan air ditemukan sangat rendah dengan kata lain stasiun transplantasi karang pada kedalaman 3 meter di stasiun 1 dan kedalaman 7 meter pada stasiun 2 sangat sesuai untuk dilakukan transplantasi karang. Kondisi ini diperkuat dengan penelitian Sahetapy (2018) yang menemukan bahwa secara umum, perairan ihamahu memiliki tingkat kekeruhan air yang rendah dan tergolong sangat sesuai untuk kehidupan biota laut.

\section{d. Suhu}

Menurut Bengen (2002), suhu rata-rata tahunan yang optimal bagi pertumbuhan karang berkisar $23-35^{\circ} \mathrm{C}$. Hasil pengukuran suhu pada kedua stasiun menunjukan yaitu pada stasiun 1 suhu mencapai $28,0^{\circ} \mathrm{C}$ dan pada stasiun 2 suhu mencapai $27,8^{\circ} \mathrm{C}$. Berdasarkan matriks kriteria parameter lingkungan biofisik perairan maka skor yang didapat untuk masing-masing stasiun adalah sama dan masuk dalam kategori sangat sesuai untuk dilakukan transplantasi karang.

\section{e. Salinitas}

Pada perairan Negeri Ihamahu, kondisi salinitas pada 10 stasiun pengamatan cukup bervariasi yaitu berkisar antara $29 \%-34 \%$ dengan rata-rata $31,2 \%$ (Siahainenia, Skk., 2017). Nilai salinitas yang bervariasi ini disebabkan oleh letak titik pengamatan itu sendiri. Pada stasiun transplantasi karang nilai salinitas juga memiliki nilai yang berbeda yaitu $31 \%$ pada stasiun 1 dan $32 \%$ pada stasiun 2. Berdasarkan Matriks kriteria parameter lingkungan biofisik perairan untuk kesesuaian rehabilitasi terumbu karang, hasil pengukuran salinitas pada kedua stasiun transplantasi karang di perairan Negeri Ihamahu sangat sesuai untuk dilakukan transplantasi karang. 


\section{f. Kecepatan Arus}

Kecepatan arus pada kedua stasiun transplantasi karang adalah berbeda. Hasil pengukuran kecepatan arus pada stasiun 1 di kedalaman 4 meter, pada bulan April mencapai $0,1 \mathrm{~cm} /$ det. Kecepatan arus 0,1 $\mathrm{cm} /$ det akan mempengaruhi transplantasi karang antara lain terhambatnya suplai makanan dan oksigen. Jika kecepatan arus lambat maka microalga yang mengancam pertumbuhan karang juga akan lebih mudah menempel pada bibit karang sehingga membuat zooxanthellae menjadi stress dan meninggalkan tubuh karang tersebut.

Pada stasiun 2 Kecepatan arus yang di ukur pada kedalaman 7 meter, pada bulan April mencapai 0,3 cm/det. Kecepatan arus ini akan menghambat penempelan microalgae pada tubuh karang. Menurut Nonjti (2007), salah satu faktor yang juga berdampak pada pertumbuhan karang yaitu arus, dimana arus sangat berfungsi untuk mendatangkan makanan bagi hewan karang berupa plankton. Berdasarkan Matriks kriteria parameter lingkungan biofisik perairan untuk kesesuaian rehabilitasi terumbu karang maka hasil pengukuran kecepatan arus pada stasiun 1 yaitu cukup sesuai untuk dilakukan transplantasi karang dan stasiun 2 sangat sesuai untuk dilakukan transplantasi karang.

\section{g. Gelombang (Ombak)}

Pergerakan gelombang yang terjadi di Perairan Ihamahu sangat dipengaruhi oleh angin/gelombang musimam. Pada akhir bulan Maret hingga akhir bulan November (Musim Timur), gelombang menjadi lebih tenang sedangkan pada bulan Desember hingga bulan februari pergerakan gelombang menjadi lebih kuat.

Gelombang yang cukup besar akan membantu pergerakan arus menyuplai makanan berupa plankton yang berguna bagi pertumbuhan dan perkembangan karang yang ditransplantasi. Selain itu, gelombang juga bisa berpengaruh negatif terhadap substrat buatan berupa blok semen karena akan berpindah dari posisi awal bahkan terbalik dan mematahkan bibit karang yang ditransplantasi.
Oleh karena itu lokasi transplantasi karang pada kedua stasiun juga telah ditentukan salah satunya berdasarkan wawancara beberapa masyarakat yang terlibat langsung dalam kegiatan rehabilitasi terumbu karang ini. Wawancara ini bertujuan agar lokasi yang ditentukan terhindar dari gelombang yang besar dan proses sedimentasi yang bisa perpengaruh negatif terhadap substrat buatan berupa blok semen ini selain pertimbangan jarak lokasi bibit indukan karang. Penempatan blok semen pada kedua stasiun transplantasi karang dilakukan pada bulan Maret. Meskipun pada kedua stasiun faktanya memiliki kondisi perairan yang bergelombang sewaktu musim timur namun tidak berdampak negatif pada blok semen. Jika ditinjau dari matriks kriteria parameter lingkungan biofisik perairan untuk kesesuaian rehabilitasi terumbu karang melalui metode transplantasi maka untuk kedua stasiun ini termasuk dalam kategori sangat sesuai untuk dilakukan transplantasi karang.

\section{h. Tipe Substrat Dasar}

Tipe substrat dasar yang dimaksud adalah substrat alami dasar perairan stasiun transplantasi karang. Berdasarkan hasil Visual di kedua stasiun transplantasi karang, maka didapatkan perbedaan kondisi substrat dasar. Pada stasiun 1, substrat dasar didominasi oleh pecahan karang (rubble) dan pasir halus, sehingga termasuk kategori cukup sesuai untuk dilakukan transplantasi karang. Sedangkan pada stasiun 2, substrat dasar sepenuhnya terdiri dari pecahan karang (rubble), sehingga stasiun 2 termasuk dalam kategori sangat sesuai untuk dilakukan transplanatasi karang.

\section{i. Paparan Terumbu}

Suharsono, $d k k$. (2013), menjelaskan bahwa pemilihan lokasi di lereng terumbu sebaiknya dipilih pada lereng terumbu yang landai atau relatif datar. Berdasarkan hasil visual, kedua stasiun transplantasi karang memiliki paparan terumbu yang relatif datar. Berdasarkan matriks kriteria parameter lingkungan biofisik perairan untuk kesesuaian rehabilitasi terumbu karang 
melalui metode transplantasi maka pada kedua stasiun termasuk kategori sangat sesuai untuk dilakukan transplantasi karang.

\section{j. Keterlindungan}

Menurut Santoso dan Kardono (2008), laut yang relatif terbuka selalu mendapat suplai makanan dan oksigen yang cukup, tetapi pada perairan yang tertutup, pertumbuhan karang batu terhalang oleh kekurangan makanan. Pada stasiun 1, termasuk dalam tipe laguna pesisir. Ciri khas dari laguna pesisir adalah memiliki bukaan sempit ke laut. Keadaan air dalam laguna ini meliputi suhu, salinitas, arus dan oksigen agak berbeda dari air terbuka.

Menurut Sahetapy (2018) lagunalaguna yang terdapat di pesisir Negeri Ihamahu selalu tergenang massa air laut ketika surut. Hal ini didukung oleh informasi dari masyarakat, bahwa Laguna Besar di Negeri Ihamahu saat terjadi pasang surut atau pasang naik kondisinya airnya tenang karena cukup terlindung dari keadaan laut di luar laguna. Berbeda dengan stasiun 2 yang relatif terbuka karena daerah ini merupakan daerah Reef Slope. Jika ditinjau dari matriks kriteria parameter lingkungan biofisik perairan untuk kesesuaian rehabilitasi terumbu karang pada stasiun 1 stasiun tergolong cukup sesuai sedangkan stasiun 2 sangat sesuai untuk dilakukan transplantasi karang.

\section{k. Penutupan Karang Batu}

Sesuai dengan matriks kriteria parameter lingkungan biofisik perairan untuk kesesuaian rehabilitasi terumbu karang melalui metode transplantasi, untuk kriteria penutupan karang sendiri harus berkisar antara $<25-<50 \%$. Kriteria ini berhubungan dengan SK Menteri Negera Lingkungan Hidup Nomor 4 Tahun 2001 yang menyatakan bahwa presentase karang hidup yang ideal untuk kegiatan transplantasi adalah $0.0 \%-24.9 \%$ (rusak) dan $25.0 \%-49.9 \%$ (sedang). Berdasarkan hasil survei Siahainenia, $d k k$. (2017), pada kedua stasiun pengamatan menunjukkan presentase terumbu karang adalah $17.32 \%$ untuk stasiun 1 dan $23.04 \%$ pada stasiun 2 . Hal ini berarti, presentase terumbu karang kedua stasiun ini tergolong rusak, sehingga dapat dijadikan lokasi transplantasi karang yang ideal.

\section{Jarak Sumber Bibit Induk Karang}

Jarak lokasi transplantasi karang dengan jarak asal indukan karang menjadi salah satu faktor yang sangat penting, karena berhubungan dengan 11 parameter penunjang pertumbuhan dan perkembangan karang yang telah dibahas sebelumnya. Pada stasiun 1, sumber bibit induk karang ke stasiun transplantasi karang berjarak $120 \mathrm{~m}$ karena faktanya bibit induk karang untuk stasiun ini langsung diambil secara acak di sekitar lokasi pengambilan data kondisi presentase karang. Berbeda dengan lokasi pengambilan bibit induk karang yang diambil secara acak pada stasiun 2 dan sekitarnya mencapai $130 \mathrm{~m}$. Berdasarkan matriks kriteria parameter lingkungan biofisik perairan untuk kesesuaian rehabilitasi terumbu karang maka pada kedua stasiun termasuk kategori sangat sesuai untuk dilakukan transplantasi karang.

Secara keseluruhan, hasil perhitungan indeks kesesuaian lahan rehabilitasi terumbu karang diperoleh bahwa Laguna Besar memiliki kesesuaian lahan rehabilitasi terumbu karang mencapai $91,67 \%$ dan kesesuaian lahan rehabilitasi terumbu karang pada "Labuang" Laguna Kipuo mencapai 100\%. Dengan demikian kedua stasiun ini dapat dijadikan lokasi transplantasi karang dengan status sangat sesuai, dengan nilai Kelas $>75-100 \%$.

\section{Daya Dukung Rehabilitasi Terumbu Karang}

Analisis daya dukung lahan dilakukan untuk mengetahui kapasitas lahan menampung jumlah teknologi substrat buatan blok semen dengan ukuran yang telah ditentukan, serta persepsi dan dukungan yang diberikan oleh masyarakat terhadap kegiatan rehabilitasi ini. Menurut Sahetapy (2016), dalam menentukan pemanfaatan kawasan sebagai lahan atau zona rehabilitasi karang diperlukan sistem rehabilitasi yang memperhitungkan daya dukung lingkungan. Pada penelitian ini, substrat yang digunakan berbentuk persegi panjang dengan ukuran mencapai $450 \mathrm{~cm}^{2} / 0,045 \mathrm{~m}^{2} / 0.0000045$ Ha. 
Tabel 3. Hasil perhitungan daya dukung lahan rehabilitasi terumbu karang

\begin{tabular}{ccccccc}
\hline $\begin{array}{c}\text { Rehabilitasi } \\
\text { Terumbu } \\
\text { Karang }\end{array}$ & $\begin{array}{c}\text { Luas } \\
\left(\mathbf{m}^{2}\right)\end{array}$ & $\begin{array}{c}\text { Luas } \\
(\mathbf{H a})\end{array}$ & $\begin{array}{c}\text { DDL } \\
\left(\mathbf{m}^{2} / \mathbf{B l o k}\right)\end{array}$ & $\begin{array}{c}\text { DDL } \\
(\mathbf{H a} / \mathbf{B l o k})\end{array}$ & $\begin{array}{c}\text { Blok yang } \\
\text { diperlukan (unit) }\end{array}$ & $\begin{array}{c}\text { Karang yang diperlukan } \\
(\mathbf{3 x 1} \text { unit blok })\end{array}$ \\
\hline Stasiun 1 & 44.500 & 4,45 & $44.449,955$ & 4,4499955 & 988.890 & 2.966 .670 \\
Stasiun 2 & 9.000 & 0,90 & $8.999,955$ & 0,8999955 & 200.000 & 600.000 \\
\hline
\end{tabular}

Luas stasiun 1 yang diperuntukan untuk transplantasi karang adalah 4,45 Ha sedangkan stasiun 2 sebesar 0,90 ha. Berdasarkan luas tersebut maka daya dukung kawasan rehabilitasi dengan metode transplantasi blok semen untuk stasiun 1 dengan luas area 4,45 $\mathrm{Ha}$ mampu mendukung 988.890 substrat buatan blok beton dengan jumlah bibit karang sebanyak 2.966.670 bibit. Pada stasiun 2 mampu mendukung 200.000 substrat buatan blok semen dan bibit karang sebanyak 600.000 bibit. Hasil perhitungan daya dukung lahan rehabilitasi terumbu karang dengan teknik transplantasi karang dapat dilihat pada Tabel 3.

Kenyataan di lapangan menunjukkan jumlah substrat buatan yang dipakai untuk transplantasi karang tidak sebanyak yang telah dihitung karena beberapa pertimbangan. Pertimbangan pertama adalah ketersedian bibit induk yang akan dipotong dan dipindahkan ke lokasi transplantasi. Pertimbangan kedua adalah stress yang dialami oleh setiap indukan karang saat dipindahkan dari tempat asal ke tempat transplantasi. Oleh karena itu untuk stasiun 1 substrat buatan yang dipakai sebanyak 28 substrat dengan jumlah bibit indukan karang yang dipindahkan sebanyak 84 bibit, sedangkan untuk stasiun 2 substrat buatan yang dipakai untuk transplantasi sebanyak 26 substrat dengan jumlah bibit sebanyak 78 bibit.

\section{Dukungan Sosial Masyarakat Terhadap Kegiatan Rehabilitasi Terumbu Karang}

Dukungan sosial masyarakat terhadap kegiatan rehabilitasi terumbu karang pada suatu perairan sangat diperlukan untuk menunjang keberhasilan kegiatan ini. Menurut Yuliani, $d k k$. (2016), dukungan masyarakat sangat penting dalam mewujudkan pengelolaan yang baik, jika pengelolaan karang dirancang dengan bijak akan dapat menjawab kebutuhan untuk melindungi dan melestarikan sumberdaya terumbu karang.
Berdasarkan hasil waancara dan kuesioner diperoleh bahwa masyarakat Negeri Ihamahu mempunyai perhatian terhadap kawasan pesisir langsung ataupun tidak langsung. Keseluruhan responden $(100 \%)$ menyatakan setuju dengan kegiatan rehabiltasi karang yang dilakukan pada kedua stasiun tersebut. Artinya bahwa kegiatan rehabaltitasi ini mendapat dukungan $100 \%$ dari masyarakat agar kondisi terumbu karang dan sumberdaya yang ada didalamnya kembali pulih. Walaupun tidak dalam waktu yang dekat tetapi masyarakat mengharapkan agar dengan kegiatan ini generasi berikutnya dapat menikmati serta memanfaatkan keberadaan sumberdaya terumbu karang.

\section{KESIMPULAN}

Berdasarkan hasl penelitian maka dapat disimpulkan sebagai berikut:

1. Laguna Besar dan "Labuang" Laguna Kipuo sangat sesuai sebagai lokasi rehabilitasi terumbu karang dengan menggunakan metode transplantasi

2. Daya dukung stasiun rehabilitasi terumbu karang menunjukkan untuk stasiun 1 memiliki luas lahan 4,45 ha yang mampu mendukung 988.890 substrat buatan. Sedangkan stasiun 2 seluas 0,90 ha mampu mendukung 200.000 substrat buatan blok semen. Dukungan sosial masyarakat terhaddap kegiatan rehabilitasi terumbu karang sebesar $100 \%$.

\section{DAFTAR PUSTAKA}

Ardiansyah, E. F., Hartoni dan Litasari, L., 2013. Kondisi Tutupan Terumbu Karang Keras dan Karang Lunak di Pulau Pramuka Kabupaten Administratif Kepulauan Seribu DKI Jakarta. Maspari Journal 5 (2), 111-118

Bengen, D. G. 2002. Ekosistem dan Sumberdaya Alam Pesisir dan Laut serta Prinsip 
Pengelolaannya. Pusat Kajian Sumberdaya Pesisir dan Lautan. IPB.

Direktorat KKJI, Dirjen KP3K, KKP R.I. 2014. SUPLEMEN 1. Panduan Identifikasi, Inventarisasi dan Pencadangan Kawasan Konservasi Perairan, Pesisir Dan PulauPulau Kecil. Jakarta.

Harvey, B.J., K.L. Nash, J. L. Blanchard, D. P. Edwards. Ecosystem-based Management of Coral Reefs Under Climate Change. Ecology and Evolution 8(12) 6354-6368.

Luthfi, O.M., P.T. Anugrah. 2017. Distribusi Karang Keras (Scleractinia) Sebagai Penyusun Utama Ekosistem Terumbu Karang di Gosong Karang Pakiman, Bawean. Depik, 6 (1): 9-22

Madduppa H., Subhan B., Arafat D, dan Zamani N.P., 2016. Riset dan Inovasi Terumbu Karang dan Proses Pemilihan Teknik Rehabilitasi: Sebuah Usulan Menghadapi Gangguan Alami dan Antropogenik Kasus Di Kepulauan Seribu. Jurnal Risalah Kebijakan Pertanian dan Lingkungan, Institut Pertanian Bogor, Vol. 3 (2): 130-139.

Nontji, A. 2007. Laut Nusantara. Djambatan. Jakarta.

Nybakken, J.W. 1992. Biologi Laut, Suatu Pendekatan Ekologis. Cetakan kedua. Jakarta. Penerbit PT. Gramedia.

Saleky D, Setyobudiandi I, Toha HA, Takdir M, Madduppa HH. 2016. Length-weight Relationship and Population Genetic of Two Marine Gastropods Species (Turbinidae: Turbo sparverius and Turbo bruneus) in The Bird Seascape Papua, Indonesia. Biodiversitas 17: 208-217.

Santoso, A. D. dan Kardono. 2008. Teknologi Konservasi dan Rehabilitasi Terumbu Karang.
Peneliti di Pusat Teknologi Lingkungan. Badan Pengajian dan Penerapan Teknologi. Jakarta. 9 (3) : 121-226.

Sahetapy, D. 2016. Penzonasian dan Penatakelolaan Kawasan Konservasi Perairan Teluk Tuhaha Berbasis Ekosistem. Proposal Disertasi. Program Doktor (S3), Program Studi Ilmu Kelautan, Pascasarjana Universitas Pattimura. Ambon. Hal: 88-92

Sahetapy, D. 2018. Rancang Bangun dan Tata Kelola Kawasan Koneservasi Teluk Tuhaha. Disertasi. Program Doktor (S3), Program Studi Ilmu Kelautan, Pascasarjana Universitas Pattimura. Ambon.

Siahainenia, L., S. F Tuhumury, P. A Uneputty, dan N. Chr. Tuhumury. 2017. Penguatan Ekonomi Masyarakat Pesisir Melalui Pengembangan dan Penerapan Model Pengelolaan "Terpadu dan Berkelanjutan" Ekosistem Laguna. Laporan Akhir Tahun Riset Terapan. Tahun I:111. Universitas Pattimura.

Suharsono, Siringoringo. M. R., Hadi. A. T., Giyanto, Yosephine. T., Budiyanto, A., dan Sulha. S. 2013. Pengembangan Teknik Transplantasi Karang di Indonesia. Pusat Penelitian Oseonografi-LIPI. Jakarta.

Sukmara, A., A. J. Siahainenia, C. Rotinsulu. 2001. Panduan Pemetaan Terumbu Karang Berbasis-Masyarakat Dengan Metode Manta Tow. Jakarta: Proyek Pesisir-CRMP Indonesia. 48p.

Yuliani, W., M. Ali S., Saputri M., 2016. Pengelolaan Ekosistem Terumbu Karang oleh Masyarakat di Kawasan Lhokseudu Kecamatan Leupung Kabupaten Aceh Besar. Jurnal Ilmiah Mahasiswa Pendidikan Biologi 1(1): 1-9. 